\title{
Residents' Performance of Single-Incision Pediatric Endo-Surgery Appendectomy (SIPESA) Versus Conventional Laparoscopic Appendectomy (CLA) in Two Centers
}

Enaam Raboei ( $\nabla$ enaamraboei@yahoo.fr)

King Fahd Armed Forces Hospital https://orcid.org/0000-0002-9865-3258

Yazeed Owiwi

King Fahd Armed Forces Hospital

Alaa Ghallab

King Fahd Armed Forces Hospital

Ameen Alsaggaf

King Fahd Armed Forces Hospital

Turki Alofi

King Fahd Armed Forces Hospital

Mazen Zidan

King Fahd Armed Forces Hospital

Ahmed Alawi

King Fahd Armed Forces Hospital

Mohamed Fayez

King Fahd Armed Forces Hospital

Hanin Shalaby

King Fahd Armed Forces Hospital

Mohamed Al Onazi

Prince Sultan Military Medical City

Mohammed Al-Mohaidly

Prince Sultan Military Medical City

Mohammed Babker

Prince Sultan Military Medical City

Saleh Kamel

Prince Sultan Military Medical City

Jawad Al-Hindi

Prince Sultan Military Medical City

Khalil Al-Batniji

Prince Sultan Military Medical City 
Ihab Omar

Prince Sultan Military Medical City

\section{Research article}

Keywords: SIPESA, CLA, Laparoscopic pediatric appendectomy

Posted Date: August 27th, 2020

DOI: https://doi.org/10.21203/rs.3.rs-64446/v1

License: (c) (1) This work is licensed under a Creative Commons Attribution 4.0 International License. Read Full License 


\section{Abstract}

Background: The outcome of SIPESA performed by surgical residents is explored once in the literature. To the best of our knowledge, there are no published studies comparing the outcome of SIPESA versus CLA performed by the surgical residents.

Aim: To assess the outcome of SIPESA at King Fahd Armed Forces Hospital (KFAFH), Jeddah versus CLA at Prince Sultan Military Medical City (PSMMC), Riyadh performed by surgical residents.

Material \& Methods: A retrospective comparative study of the outcome of SIPESA versus CLA conducted in two centers from January 2011 to July 2018. The two groups were compared for age, seniority of operating surgeon, mean operative time (MOT), perioperative complications and length of hospital stay (LOS).

Results: 136 appendectomies (83(61\%) SIPESA \& 53(39\%) CLA) were performed by residents between January 2011 and July 2018 in both centers. Postoperative complications were reported in $3.8 \%$ of CLA and $3.6 \%$ of SIPESA. There was no significant difference in postoperative complications between the two groups. The MOT of SIPESA and CLA was 92.25 minutes \& 87.85 minutes respectively.

Conclusion: SIPESA and CLA performed by residents are equally safe and feasible with no added morbidity. We believe that this good outcome is related to the adequate supervision of residents by experienced surgeons in conjunction with a properly structured training program. There was no significant difference in the outcome of both groups.

\section{Background:}

Most centers advocate laparoscopy for acute appendicitis to minimize the size and the number of skin incisions even for complicated appendicitis ${ }^{1}$. SIPESA, which was described for the first time by Pelosi in 19922 ; and CLA are the most common procedures used in laparoscopic appendectomy. SIPESA gives easy and quick access for an incidental finding of intrabdominal anomalies, by removing the SIPESA port and performing the procedure extracorporeal.

Many comparative studies, a systematic review and pooled analysis demonstrated that single-incision laparoscopic appendectomy (SILA) is comparable to CLA in adults. These studies identified the need for randomized controlled trials to clarify the efficacy of SILA compared to CLA. RCTs comparing SIPSA to CLA showed that there is no difference except for the longer operative time ${ }^{3}$. SIPESA in pediatric patients has gained significant popularity because of its preferable cosmetic result which was not proved for SIPSA on long term follow up ${ }^{4,5}$. Previous studies have typically compared SIPESA \& CLA appendectomy in children and have shown heterogeneous results ${ }^{6}$. There is no difference in the LOS or postoperative complications ${ }^{5,7}$. The longer MOT was the main concern of SIPESA $A^{6}$. One study has shown that SIPESA in children is safe and feasible when performed by residents versus fellows ${ }^{8}$. We have started SIPESA in 2011 and it became our standard approach for acute appendicitis. The residents have the priority in 
performing SIPESA in our institute. It is a challenging process for any center to balance between residency training curriculum and patient safety. To the best of our knowledge, this is the first study to assess the outcome of SIPESA versus CLA undertaken by residents.

\section{Aim}

To assess the outcome of appendectomy performed by surgical residents. We compared the outcome of SIPESA at King Fahd Armed Forces Hospital (KFAFH), Jeddah versus CLA at Prince Sultan Military Medical City (PSMMC), Riyadh.

\section{Material \& Methods:}

A retrospective comparative study conducted at KFAFH, Jeddah, and PSMMC, Riyadh, Saudi Arabia from January 2011 to July 2018. Medical students collected data from electronic records of all children below 14 years of age. Laparoscopic appendectomy was performed by residents in both centers. SIPESA is the preferred approach for acute appendicitis at KFAFH while CLA is preferred at PSMMC. All incidental appendectomies were excluded from the study. SIPESA was performed through a $1.5 \mathrm{~cm}$ umbilical incision using single-incision Medtronic SILS ${ }^{\text {TM }}$ port. We applied endo-loops to the base of the appendix after controlling the meso-appendix mainly by hook diathermy with the aid of LigaSure TM device in complicated cases. The appendix was divided and retrieved through SIPESA port. All patients received IV Paracetamol (15 mg/kg q $8 \mathrm{~h}$ ) and IM Tramadol (1 mg/kg q8h) postoperatively. All CLA patients were routinely catheterized before the operation to avoid urinary bladder injury as they routinely use Veress needle. CLA was undertaken using the standard approach with the first $5 \mathrm{~mm}$ umbilical port and the other two ports were inserted in supra-pubic and left iliac fossa under vision. Ligation of the appendicular base was done with endoloops after division of the meso-appendix with diathermy hook. The appendix was extracted by endobag to avoid contaminating the wound. All patients received IV Paracetamol $(15 \mathrm{mg} / \mathrm{kg}$ q8h) and IV Morphine infusion (10-20 mic/kg/hr) postoperatively. Pain was assessed by using the Facial Action Coding System (FACS) in both groups ${ }^{8}$.

The two groups were compared for seniority of operating surgeon, MOT, post-operative pain, duration of analgesia, postoperative complications, and LOS. A statistician analyzed the data by using Statistical Package for Social Science (SPSS) version 22. Descriptive statistics were used to summarize collected data. We reported frequency and percentages of categorical variables. We applied the reported descriptive statistics include mean, standard deviation (SD), median and inter-quartile range (IQR) for numerical variables. Distributions of continuous variables were examined to assess normality. We found the variables did not follow a normal distribution; therefore, non-parametric inferential tests were used. Comparison between SIPESA and CLA was performed using inferential statistical analysis. Categorical variables were compared using chi-square tests or Fisher's Exact test where small frequencies were reported. Numerical variables were compared using the Mann-Whitney test or independent samples t-test depending on normality of data distribution. 


\section{Results:}

One hundred thirty-six appendectomies performed by residents were included in the analysis. The majority $(83,61 \%)$ of the procedures was SIPESA at KFAFH, and the rest $(53,39 \%)$ were CLA at PSMMC. The difference between surgical techniques and location is statistically significant, Fisher's Exact test $p$ $<.001$. Provisional diagnosis showed similarity between surgical techniques with the majority of cases being simple appendicitis ( $92 \%$ of SIPESA and $83 \%$ of $C L A$ ), $X^{2}(1)=2.28, p=.13$, age (Mann-Whitney $p$ $=.22)$ or gender $\left(X^{2}(1)=0.001, p=.97\right)$. The MOT was 92.25 and 87.85 minutes for SIPESA and CLA respectively $t(134)=1.51, p=.13$. Histopathological examination confirmed acute appendicitis in $93 \%$ of SIPESA and $91 \%$ of CLA respectively $X^{2}(1)=0.12, p=.65$. There was a leucocytosis in $89 \%$ of SIPESA and $94 \%$ of $\operatorname{CLA~X} X^{2}(1)=1.08, p=.30$. Ultrasound confirmed the diagnosis of acute appendicitis in $49 \%$ of CLA and $43 \%$ of SIPESA cases respectively $X^{2}(1)=0.42, p=.52$. CT confirmed acute appendicitis in $15 \%$ of SIPESA and $11 \%$ of CLA cases respectively $X^{2}(1)=0.28, p=.60$ (Table 1 ). LOS was 2.8 and 3.6 days in SIPESA and CLA respectively $p=.31$. Post-operative complications was reported in $3.8 \%$ and $3.6 \%$ of CLA and SIPESA respectively Exact test $p=.75$. There was no statistically significant difference between the two groups in any of the variables. 
Table 1

Patient demographic characteristics / Characteristics of the surgeries

\begin{tabular}{|c|c|c|c|}
\hline \multirow[t]{2}{*}{ Characteristics } & \multicolumn{2}{|l|}{ Surgery type } & \multirow[t]{2}{*}{ Comparison test } \\
\hline & SIPESA $(n=83)$ & $\operatorname{CLA}(n=53)$ & \\
\hline Location (Institute) & & & Fisher's test $p<.001$ \\
\hline KFAFH & $83(100 \%)$ & $0(0 \%)$ & \\
\hline PSMMC & $0(0 \%)$ & $53(100 \%)$ & \\
\hline \multirow[t]{2}{*}{ Patient age, years } & $10(9-11)$ & $11(9-12)$ & $M-W$ test $p=.22$ \\
\hline & $9.55 \pm 2.32$ & $10.04 \pm 2.10$ & \\
\hline \multicolumn{4}{|l|}{ Gender } \\
\hline Male & $53(64 \%)$ & $34(64 \%)$ & $X^{2}(1)=0.001$ \\
\hline Female & $30(36 \%)$ & $19(36 \%)$ & $p=.97$ \\
\hline Provisional diagnosis & $76(92 \%)$ & $44(83 \%)$ & $X^{2}(1)=2.28, p=.13$ \\
\hline Simple appendicitis & $7(8 \%)$ & $9(17 \%)$ & \\
\hline \multicolumn{4}{|l|}{ Complicated appendicitis } \\
\hline \multirow[t]{2}{*}{ Operative time, minutes } & $90(82-105)$ & $90(60-104)$ & $t(134)=1.51, p=.13$ \\
\hline & $96.25 \pm 30.91$ & $87.85 \pm 32.79$ & \\
\hline Histopathology & & & $X^{2}(1)=0.12, p=.65$ \\
\hline Negative specimen & $6(7 \%)$ & $5(9 \%)$ & \\
\hline Positive for acute appendicitis & $77(93 \%)$ & $48(91 \%)$ & \\
\hline WBC group & & & $X^{2}(1)=1.08, p=.30$ \\
\hline Negative & $9(11 \%)$ & $3(6 \%)$ & \\
\hline Positive & $74(89 \%)$ & $50(94 \%)$ & \\
\hline US confirmed & $36(43 \%)$ & $26(49 \%)$ & $X^{2}(1)=0.42, p=.52$ \\
\hline CT scan confirmed & $12(15 \%)$ & $6(11 \%)$ & $X^{2}(1)=0.28, p=.60$ \\
\hline
\end{tabular}


Table 2

Post-operative recovery

\begin{tabular}{|c|c|c|c|}
\hline \multirow[t]{3}{*}{ Characteristics } & \multicolumn{2}{|l|}{ Surgery type } & \multirow[t]{3}{*}{ Comparison test } \\
\hline & SIPESA & CLA & \\
\hline & $(n=83)$ & $(n=53)$ & \\
\hline \multirow[t]{2}{*}{ LOS, days } & $2(2-3)$ & $3(1-5)$ & \multirow[t]{2}{*}{$M-W$ test $p=.31$} \\
\hline & $2.80 \pm 2.11$ & $3.60 \pm 3.13$ & \\
\hline Use of IV antibiotic & 77 (95\%) & $50(96 \%)$ & Fisher's test $p=1.00$ \\
\hline \multirow[t]{2}{*}{ Duration of antibiotic use, days } & $5(3-7)$ & $3(1-5)$ & \multirow[t]{2}{*}{$M-W$ test $p=.002$} \\
\hline & $5.85 \pm 3.98$ & $3.66 \pm 3.02$ & \\
\hline \multirow[t]{2}{*}{ Duration of analgesia, days } & $5(3-7)$ & $3(2-5)$ & \multirow[t]{2}{*}{ M-W test $p<.001$} \\
\hline & $5.81 \pm 3.10$ & $3.51 \pm 2.17$ & \\
\hline \multicolumn{3}{|l|}{ Post-operative complications } & \multirow[t]{5}{*}{ Fisher's test $p=.84$} \\
\hline No complications & $80(96.4 \%)$ & $51(96.2 \%)$ & \\
\hline Intra-abdominal collection & $1(1.2 \%)$ & $2(3.8 \%)$ & \\
\hline Adhesions & $1(1.2 \%)$ & $0(0 \%)$ & \\
\hline Pleural effusion & $1(1.2 \%)$ & $0(0 \%)$ & \\
\hline
\end{tabular}

\section{Discussion:}

CLA is the gold standard approach in most pediatric centers. Appendectomy is the commonest procedure done by SILS. Nowadays, SIPESA is gaining popularity and is well-known for its cosmetic result $9,10,11,12,13,14,15$.

As our study is retrospective and comparative between two training centers, the data collection was completed independently. There was a structured method for collecting the data by medical students. Results were analyzed by a statistician. Although SIPESA is considered as an accepted approach for appendectomy, its impact on the residency training program was not explored in detail. However, there is a general impression that surgery performed by a junior surgeon has worse outcome, but our results showed a good outcome with an acceptable complication rate. A major limitation of this study is that the comparison between SIPESA and CLA is effectively a comparison between KFAFH and PSMMC. The difference between surgical approaches and location in our study is statistically significant, Fisher's Exact test $p<.001$ ). The patient demographics were comparable between SIPESA and CLA groups, with similar patient ages and gender distribution (Table.1). The $30^{\circ}$ cameras, energy source (electrocautery), 
mesoappendix dissection, and endoloop ligation of the appendicular stump were similar in both techniques. The postoperative analgesia protocol was different between CLA and SIPESA, but fortunately, there was a good postoperative pain control in both groups. The LOS was equal in both groups. The negative appendectomies were comparable in both groups.

It is known that the severity of appendiceal inflammation is one of the difficult factors that influencing the appendectomy outcomes. There was no significant statistical difference in the rate of complicated appendicitis in both groups. In contrast to adults, we do not consider obesity or complicated appendicitis as contraindications to SIPESA ${ }^{2}$. We did not have any incisional hernia in either group (Table.2).

The MOT of SIPESA undertaken by our resident is not significantly longer than CLA as reported in other publications $16,17,18,19,20,21,22,23$. This may be explained by techniques we developed to overcome instrument collision such as changing the placement of instruments in the SILS port, rotating the port clockwise and anticlockwise depending on the direction of traction of the appendix. We also undertake continuous training in SILS (dry and wet laboratory workshops) for our residents. The use of flexible articulating instead of straight instruments may overcome the technical difficulty ${ }^{12,13}$. We prefer to use straight laparoscopic instruments and a long laparoscope $(50 \mathrm{~cm})$ as it makes the camera holder away from the operative field and decreases the collision of instruments.

There was no significant difference in morbidity and mortality between the two groups in our study as previously reported ${ }^{3}$. Also there was no conversion to open in either technique.

We consider SIPESA as a good training model for surgical residents to build up their SIPES experience as it is the commonest surgical emergency. The good outcome is multifactorial including the basic laparoscopic background, supervision by the senior surgeon, and structured training workshops.

\section{Conclusion:}

This study suggests that SIPESA performed by residents is feasible and safe even for complicated appendicitis with no added morbidity. The technique can be imparted satisfactorily to residents with successful implementation in structured surgical training programs.

\section{Declarations}

\section{Funding Sources}

This study was not funded by any company.

\section{Conflict of Interest Statement}

Author Enaam Raboe, declares that she has no conflict of interest.

Author Yazeed Owiwi, declares that he has no conflict of interest 
Author Alaa Ghalab, declares that he has no conflict of interest

Author Ameen Alsaggaf, declares that he has no conflict of interest

Author Mazen Zidan, declares that he has no conflict of interest

Author Ahmed Alawi, declares that he has no conflict of interest

Author Mohamed Fayez, declares that he has no conflict of interest

Author Mohamed Al Onazi MD², declares that he has no conflict of interest.

Author Mohammed Al-Mohaidly MD², declares that he has no conflict of interest.

Author Mohammed Babiker $\mathrm{MD}^{2}$, declares that he has no conflict of interest.

Author M. Saleh Kamel MD², declares that he has no conflict of interest.

Author A. Jawad Al-Hindi MD², declares that he has no conflict of interest.

Author Khalil Al-Batniji MD², declares that he has no conflict of interest.

Author Ihab Omer Ali MD², declares that he has no conflict of interest.

Author Hanin Shalaby, declares that she has no conflict of interest

\section{Statement of Ethics:}

All procedures performed in studies were in accordance with the ethical standards of the institutional and/or national research committee and with the 1964 Helsinki declaration and its later amendments or comparable ethical standards and approved by hospital IRB.

\section{Author Contributions}

\section{Enaam Raboei MD ${ }^{1}$ Corresponding Author:}

Drafting the work

Final approval of the version to be published

Agreement to be accountable for all aspects of the work in ensuring that questions related to the accuracy; or the acquisition; and revising it critically for important intellectual content;

\section{Yazeed Owiwi MD ${ }^{1}$ co-author:}

Substantial contributions to the conception or design of the work 


\section{Alaa Ghalab MD ${ }^{1}$ co-author}

Substantial contributions to the conception or design of the work

\section{Ameen Alsaggaf $\mathrm{MD}^{1}$ co-author:}

Integrity of any part of the work are appropriately investigated and resolved

\section{Mazen Zidan MD ${ }^{1}$ co-author}

Integrity of any part of the work are appropriately investigated and resolved

\section{Ahmed Alawi MD ${ }^{1}$ co-author:}

Review, drafting, and final approval of the manuscript.

\section{Mohamed Nagem MD ${ }^{1}$ co-author:}

Review, drafting, and final approval of the manuscript.

\section{Hanin Shalaby MSc HI ${ }^{1}$ co-author :}

Analysis, or interpretation of data for the work

Co-Author Mohamed Al Onazi MD², In charge of PSMMCC team writing and interpreting the data and reviewing the last manuscript for approval

Co-Author Mohammed Al-Mohaidly MD², PSMMC team member In charge of PSMMCC team writing and interpreting the data and reviewing the last manuscript for approval

Co-Author Mohammed Babiker MD², PSMMC team member. In charge of PSMMCC team writing and interpreting the data and reviewing the last manuscript for approval

Co-Author M. Saleh Kamel MD², PSMMC team member. In charge of PSMMCC team writing and interpreting the data and reviewing the last manuscript for approval

Co-Author A. Jawad Al-Hindi MD², PSMMC team member. In charge of PSMMCC team writing and interpreting the data and reviewing the last manuscript for approval

Co-Author Khalil Al-Batniji MD², PSMMC team member. In charge of PSMMCC team writing and interpreting the data and reviewing the last manuscript for approval

Co-Author Ihab Omer Ali MD², PSMMC team member. In charge of PSMMCC team writing and interpreting the data and reviewing the last manuscript for approval 


\section{Type of Study:}

Treatment Studies

\section{Levels of Evidence: IV}

\section{References}

1. Muenster O, Puga Nougues C, Adibe O, Amin S, Georgeson K, Harmon C. Appendectomy using singleincision pediatric endosurgery for acute and perforated appendicitis. Surgical Endoscopy. 2010;24(12):3201-3204.

2. Sesia S, Haecker F, Kubiak R, Mayr J. Laparoscopy-Assisted Single-Port Appendectomy in Children: Is the Postoperative Infectious Complication Rate Different?. Journal of Laparoendoscopic\& Advanced Surgical Techniques. 2010;20(10):867-871.

3. St. Peter S, Adibe O, Juang D, Sharp S, Garey C, Laituri C et al. Single Incision Versus Standard 3-Port Laparoscopic Appendectomy. Annals of Surgery. 2011;254(4):586-590.

4. Daniel J Ostlie, Nicole E Sharp, Priscilla Thomas, Shawn D St. Peter. Patient Scar Assessment After Single-Incision Versus Four-Port Laparoscopic Cholecystectomy: Long-Term Follow-Up from a Prospective Randomized Trial. June 2013. J Laparoendosc Adv Surg Tech A. 2013 Jun;23(6):553-5. DOI: 10.1089/lap.2013.0245

5. Gasior AC, Knott EM, Holcomb GW, Ostlie DJ, St Peter SD. Patient and parental scar assessment after single-incision versus standard 3-port laparoscopic appendectomy: long-term follow-up from a prospective randomized trial. J Pediatr Surg. 2014;49:120e122. discussion 122.

6. Feng J, Cui N, Wang Z, Duan J. Bayesian network metaanalysis of the effects of singleincision laparoscopic surgery, conventional laparoscopic appendectomy and open appendectomy for the treatment of acute appendicitis. Experimental and Therapeutic Medicine. 2017.

7. Perez EA, Piper H, Burkhalter LS, Fischer AC. Single-incision laparoscopic surgery in children: a randomized control trial of acute appendicitis. Surg Endosc. 2013;27:1367e1371.

8. Wakasugi M, Tsujimura N, Nakahara Y, Matsumoto T, Takemoto H, Takachi K et al. Single-incision laparoscopically assisted appendectomy performed by residents is safe and feasible: A singleinstitution, retrospective case series. Annals of Medicine and Surgery. 2017;15:43-46

9. Yannam G, Griffin R, Anderson S, Beierle E, Chen M, Harmon C. Single-incision pediatric endosurgery (SIPESA) appendectomy-is obesity a contraindication?. Journal of Pediatric Surgery. 2013;48(6):1399-1404.

10. Karan Sikka, Alex A. Ahmed, Damaris Diaz, Matthew S. Goodwin, Kenneth D. Craig, Marian S. Bartlett, Jeannie S. Huang. Automated Assessment of Children's Postoperative Pain Using Computer Vision. Pediatrics; July 2015, VOLUME 136 / ISSUE 1

11. Fransen SA, Broeders E, Stassen L, Bouvy N. The voice of Holland: Dutch public and patient's opinion favours single-port laparoscopy. J Minim Access Surg. 2014;10:119-25. 
12. NereoVettoretto Email author and Vincenzo Mandalà. Single port laparoscopic appendectomy: are we pursuing real advantages? World Journal of Emergency Surgery201, 6:25.

13. Canes D, Desai M, et al (2008): Transumbilical Single-Port Surgery: Evolution and Current Status . Eur Urol. Nov;54(5):1020-9

14. Ponsky TA, Diluciano J, et al (2009) Early experience with single-port laparoscopic surgery in children. J Laparoendosc Adv Surg Tech. Aug;19(4):551-3.

15. Tsai AY, Selzer DJ (2010): Single-port laparoscopic surgery. Adv Surg. 44:1-27.

16. Dutta S. (2009) Early experience with single-incision laparoscopic surgery: eliminating the scar from abdominal operations. J Pediatr Surg. Sep;44(9):174

17. Martin Salö1 *, Emil Järbur1, Mette Hambraeus1, Bodil Ohlsson2, Pernilla Stenström1 and Einar Arnbjörnsson. Two-trocar appendectomy in children - description of technique and comparison with conventional laparoscopic appendectomy. BMC Surgery (2016) 16:521-5.

18. Wu K, Yang L, Wu A, et al. Single-site laparoscopic appendectomy in children using conventional instruments: a prospective, randomized, control trial. Pediatr Surg Int. 2015;31:167e171.

19. Guillermo Duza, MD, Mariano Palermo, MD, FACS, Elbert Khiangte, Mohammad Azfar, FRCSEd, FACS, Syed Amjad Ali Rizvi, FRCSEd, Nelson Trelles, MD, Luis A. Blanco, MD, Jose Menendez, MD, Leonardo Abramson, MD, Mohamed Sbai-Idrissi, MD. Single port laparoscopic appendectomy vs conventional laparoscopic appendectomy: outcomes after multicenter randomized control trial. Journal of American College of Surgeons. October 2015Volume 221, Issue 4, Supplement 2, Page e17.

20. Buicko JL1, Feng J, Cui N, Wang Z, Duan J. Bayesian network metaanalysis of the effects of singleincision laparoscopic surgery, conventional laparoscopic appendectomy and open appendectomy for the treatment of acute appendicitis. Exp Ther Med. 2017 Dec; 14(6): 5908-5916

21. Park J, Kwak H, Kim SG, Lee S. Single-port laparoscopic appendectomy: comparison with conventional laparoscopic appendectomy. J Laparoendosc Adv Surg Tech A. 2012;22:142-145.

22. Yu-Long Cai, Xian-Ze Xiong, Si-Jia Wu, Yao Cheng, Jiong Lu, Jie Zhang, Yi-Xin Lin, and Nan-Sheng Cheng. Single-incision laparoscopic appendectomy vs conventional laparoscopic appendectomy: Systematic review and meta-analysis. World J Gastroenterol. 2013 Aug 21; 19(31): 5165-5173.

23. Wieck M, Hamilton N, Krishnaswami S. A cost and outcome analysis of pediatric single-incision appendectomy. Journal of Surgical Research. 2016;203(2):253-257.

24. Jongkyung Park. Huiyong Kwak. Sung Geun Kim. Seong Lee. Single-Port Laparoscopic Appendectomy: Comparison with Conventional Laparoscopic Appendectomy. December 2011, Journal of Laparoendoscopic\& Advanced Surgical Techniques 22(2):142-5 